\title{
Análise do efeito do G-CSF sobre a geração de células dendríticas tolerogênicas in vitro $e$ a ação dessas células in vivo durante a evolução clínica de Neurite Experimental Autoimune.
}

\author{
Alessandro dos Santos Farias (PQ), Fernando Pradella (PG), Gleici Branco (IC)
}

\section{Resumo}

A síndrome de Guillian-Barré (SGB) é uma doença inflamatória aguda do sistema nervoso periférico, sendo a Neurite experimental Autoimune (EAN) o modelo animal de estudo [3]. Busca-se então investigar os mecanismos pelos quais o G-CSF diminui a gravidade da EAN, avaliando o potencial tolerogênico das células dendríticas (DCs) geradas na presença de G-CSF, bem como sua capacidade em controlar a evolução da doença. Nossos resultados indicam alteração do fenótipo na expressão de CD11b e CD11c das DCs cultivadas com G-CSF em relação ao controle, assim como expressão diferenciada de TGFb e receptores de quimiocinas. Há também evidências de atenuação da gravidade da doença nos animais que receberam DCs cultivadas na presença de G-CSF em relação aos animais que receberam DCs cultivadas na ausência do fator, indicando que a terapia celular com DCs tratadas com G-CSF pode amenizar a gravidade da doença em animais com EAN.

Palavras Chave: EAN, células dendríticas, G-CSF.

\section{Introducão}

As neuropatias inflamatórias desmielinizantes do sistema nervoso periférico, como a síndrome de Guillain-Barré resultam de resposta imune inadequada. A Neurite experimental Autoimune (EAN), devido à sua enorme similaridade com a SGB, proveu a maioria do conhecimento que se tem sobre tal síndrome. Já se descreveu potentes efeitos do G-CSF, um fator hematopoiético, sobre a geração de células $T$ [2]. O presente projeto tem por objetivo avaliar o efeito do G-CSF sobre a geração de células dendríticas e o efeito dele sobre as funções efetoras de células neuritogênicas durante a evolução clínica da EAN.

\section{Resultados e Discussão}

Nossos resultados, ainda que parciais, indicam que DCs cultivadas com G-CSF a partir do $7^{\circ} \mathrm{e}$ $12^{\circ}$ dia tem o fenótipo alterado em relação às células controle, com alteração na expressão de CD11b e CD11c, principalmente na indução de mais células CD11 $\mathrm{b}^{+}$e menos CD11 $\mathrm{b}^{+}$CD11 $\mathrm{c}^{+}$.

Além disso, DCs cultivadas com G-CSF a partir do $7^{\circ}$ dia produzem mais TGFb, citocina antiinflamatória, que as células controles, e têm a expressão gênica de importantes receptores de quimiocinas regulados negativamente. CCR2 e CCR5, em especial, são considerados receptores de quimiocinas proinflamatórias, e sua expressão permitiria que as DCs respondessem aos estímulos inflamatórios [1].

Os resultados também mostraram uma atenuação acentuada da gravidade da doença nos animais que receberam células dendríticas cultivadas na presença de G-CSF a partir do $12^{\circ}$ dia de cultura (figura 1), não sendo o tratamento dose dependente.

Figura 1. Comparação da evolução clínica da EAN em diferentes grupos.

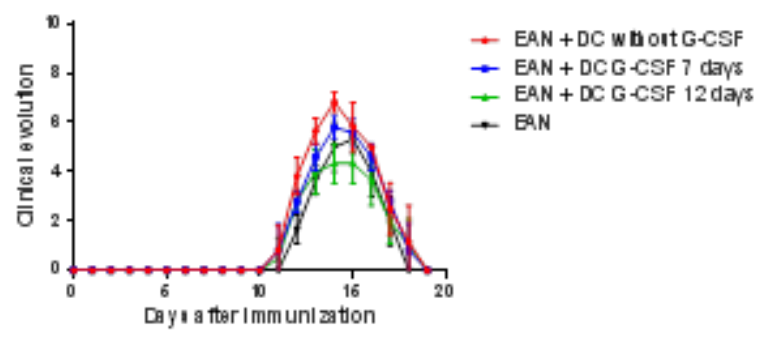

\section{Conclusões}

Nossos resultados, apesar de ainda preliminares, mostraram que a terapia celular com DCs tratadas com G-CSF é capaz de reduzir a gravidade da doença em animais com EAN.

\section{Agradecimentos}

Esse trabalho foi apoiado por subsídios da FAPESP

\footnotetext{
${ }^{1}$ Cravens PD1, Lipsky PE. Dendritic cells, chemokine receptors and autoimmune inflammatory diseases. Immunol Cell Biol. 2002 Oct;80(5):497-505.

${ }^{2}$ Pradella F, Moraes AS, Santos MP, Depaula RF, Degaki KY, Longhini AL, Silva VD, Santos LM, Farias AS. Granulocyte-colonystimulating factor treatment enhances Foxp3(+) T lymphocytes and modifies the proinflammatory response in experimental autoimmune neuritis. CNS Neurosci Ther. 2013 Jul;19(7):529-32.

${ }^{3}$ Waksman BN, Adam RD: Allergic neuritis: an experimental disease of rabbits induced by the injection of peripheral nervous tissue and adjuvant. J. Exp.Med. 1955, 102:213:225.
} 